\title{
Is Dentistry at Risk? A Case for Interprofessional Education
}

\author{
Rebecca S. Wilder, B.S.D.H., M.S.; Jean A. O'Donnell, D.M.D.; J. Mark Barry, \\ D.M.D., M.B.A.; Dominique M. Galli, M.S., Ph.D.; Foroud F. Hakim, D.D.S., M.B.A.; \\ Lavern J. Holyfield, D.D.S.; Miriam R. Robbins, D.D.S., M.S.
}

Abstract: The goal of interprofessional education (IPE) is to bring various professional groups together in the educational environment to promote collaborative practice and improve the health care of patients. Interest in IPE has been sparked by several factors in the health care system, including the increased awareness of oral-systemic connections, an aging population, the shift of the burden of illness from acute to chronic care, and lack of access to basic oral care. Increasingly, since the publication of the U.S. surgeon general's report in 2000, the dialogue surrounding IPE in dentistry has escalated. But how has dentistry changed regarding IPE since the report was released? This position paper argues that little has changed in the way dental students are taught and prepared to participate in IPE. The authors contend that academic dentistry and organized dentistry must take the lead in initiating and demanding IPE if dental students are to be prepared to work in the health care environment of the twenty-first century. Included are reasons why IPE is necessary and why dentistry must lead the conversation and participate in the solution to the oral health care crisis. It explores existing models and alternate approaches to IPE, barriers to implementation, and proposed strategies for academic institutions.

Prof. Wilder is Associate Professor, Director of Faculty Development, and Director of Graduate Dental Hygiene Education, University of North Carolina at Chapel Hill School of Dentistry; Dr. O'Donnell is Assistant Professor and Vice Chair, Department of Restorative Dentistry and Comprehensive Care, University of Pittsburgh School of Dental Medicine; Dr. Barry is Associate Dean of Clinical Administration, Medical University of South Carolina; Dr. Galli is Associate Professor, Department of Oral Biology, Indiana University School of Dentistry; Dr. Hakim is Assistant Professor and Curriculum Director, Department of Restorative Dentistry, University of the Pacific Arthur A. Dugoni School of Dentistry; Dr. Holyfield is Director of Faculty Development and Assistant Professor, Baylor College of Dentistry; and Dr. Robbins is Associate Chair, Department of Oral and Maxillofacial Pathology, Radiology, and Medicine, New York University College of Dentistry. Direct correspondence and requests for reprints to Prof. Rebecca S. Wilder, University of North Carolina at Chapel Hill School of Dentistry, CB\#7450, Room 3280, Chapel Hill, NC 27599-7450; 919-966-8221 phone; 919-966-6761-fax; Rebecca_wilder@dentistry.unc.edu.

This article was written in partial fulfillment of completion of the 2007-08 ADEA Leadership Institute.

Key words: dental education, interprofessional education, curriculum reform, predoctoral education, interdisciplinary education

Submitted for publication 3/17/08; accepted 7/23/08

$\mathrm{T}$ The phrase "the mouth is a mirror" has been used to illustrate what can be detected and ultimately diagnosed from examining oral tissues, including the detection of microbial infections, hematological diseases, and some cancers. As the challenge of providing health care to all Americans is growing, so is the disconnect between the dominant pattern of practice of the dental profession and the oral health needs of the nation. ${ }^{1}$ In fact, dental disease is so widespread that the U.S. surgeon general's report on oral health referred to it as the "silent epidemic.".

Concern over such oral health issues as the prevalence of dental disease, the relationship between oral health and general health, and the limited availability of dental health professionals to meet the oral health care needs of U.S. citizens is escalating. We submit that if dental health professionals are to remain the vanguard of oral health care, it is imperative that they implement strategies to address the oral health needs of the population. One such measure that has been suggested to achieve this goal is interprofessional collaboration, a cross-disciplinary approach to patient care across various professions.

The report Oral Health in America critically reviewed the relationship among oral health, general health, and well-being. ${ }^{2}$ This report called for the development of a National Oral Health Plan that will "improve quality of life and eliminate health disparities by facilitating collaborations among individuals, health care providers, communities, and policymakers at all levels of society and by taking advantage of 
existing initiatives." To be included in this oral health plan, the dental profession must be vigilant in efforts to prepare itself for collaborative care. This will be difficult to accomplish if health care providers have not been trained to work in interprofessional teams, a process that commences with the incorporation of interprofessional education into the dental education curriculum.

The term "interprofessional education" (IPE) (also known as interdisciplinary education) is defined as an educational process that provides health professions students "with experience across professional disciplinary lines as they acquire knowledge and skills in subject areas required in their respective educational programs." ${ }^{\text {'3 }}$ While there are documented instances of institutions across the nation and across multiple health care disciplines that engage in IPE, it is the premise of this position paper that participation by dental institutions in these efforts is insufficient and that nondental entities are proceeding with and without the input or influence of the dental profession. ${ }^{4,5}$ Further, we submit that unless the current philosophy of dental education and practice is changed, future oral health care providers will be excluded from interprofessional care. ${ }^{6-8}$

In 2002, for example, 150 leaders and experts from various health professions convened at the Institute of Medicine (IOM) Health Professions Education Summit to discuss strategies for restructuring clinical education to be congruent with principles of the current and future health care system. The summit was followed by a report, Health Professions Education: A Bridge to Quality, ${ }^{4}$ which emphasized that physicians, nurses, pharmacists, and other health care professionals are not being adequately prepared to provide the highest quality of care nor is there adequate attention to assessing the professionals' continued proficiency. The report laid out five core competencies that all clinicians should possess to achieve the level of care needed in the twenty-first century. The proposed competencies were 1) provide patient-centered care; 2) work in interdisciplinary teams; 3) practice evidence-based medicine; 4) focus on quality improvement; and 5) utilize information technology. Represented at the summit were physicians, pharmacists, nurses, physician assistants, and allied health professionals. Dentistry had no representation on any level of the planning committee nor among attendees at the summit. ${ }^{5}$

In 2004, Zwarenstein et al. reported on a Cochrane review to assess the effectiveness of IPE interventions compared to education interventions in which groups of students from various professions learn separately from one another. ${ }^{9}$ At that time, no studies fulfilled the inclusion criteria for the systematic review process. More recently, Reeves et al. reported on the results of a follow-up Cochrane review on IPE. ${ }^{10}$ Several health and social professionals were included in the criteria for selection: physicians, nurses, midwives, pharmacists, dentists, and others. Six studies met the inclusion criteria. Of those studies, several showed positive results of IPE in areas including patient satisfaction ${ }^{11}$ and collaborative team behavior. ${ }^{12}$ Unfortunately, dentistry was not studied in any of the investigations.

In 2006, Rafter et al. reported on the status of IPE in U.S. academic health centers that include schools of dentistry. ${ }^{5}$ Of the academic health centers investigated, several reported attempting to develop IPE programs but none of them included dental students. While reasons cited for dentistry not participating in IPE vary (lack of time, resources, interest, administrative support), if academic dentistry does not make a concerted effort to incorporate IPE into the dental curriculum and participate in the planning and implementation of IPE, the profession will remain left behind.

\section{A Wake-Up Call}

Concern for the nation's oral health is escalating. Issues include access to care for low-income and underserved minority groups, oral diseases related to tobacco use, chronic facial pain, craniofacial birth defects and trauma, and the emergent health needs of an aging population that will need services in new locations and in new forms. ${ }^{1}$ A recent article in the New York Times highlighted oral health disparities, ${ }^{13}$ reporting that while dentists are experiencing a financial boom, millions of Americans are without access to care. This article was just one attempt to capture the attention of the American public; but it should also serve as a wake-up call for the profession to accept that change is needed. In essence, the dental profession can no longer continue business as usual in the delivery of patient care.

One approach that should be considered in the delivery of oral health care is collaboration with other members of the medical team. The perception that oral health is separate from and less important than general health has been ingrained in the American consciousness. Private practice settings and isolation from other health services have helped create the 
impression that oral health is not part of one's overall health but rather a luxury available only to those who have access through employee coverage and/or the ability to pay for services. However, oral health and general health are inseparable.

Routine dental visits are an important aspect of patient health. Dentists are often the first line of defense in the prevention, early detection, and treatment of both oral and systemic diseases and therefore must become more involved in assessing and ensuring the overall health of their patients through screening, diagnosis, and referral. Moreover, a collaborative network among dentists and other medical professionals would be even more beneficial to patients as well as to other health care providers. This collaboration begins with the preparation of dental students to work effectively in alliances with other health professionals and will require support at all levels of dental education, beginning at the highest levels of administration.

The need for interprofessional health care is made more acute by the insufficient number of available dental professionals in rural and underserved areas to address the needs of the general population. IPE is an innovative measure that can resolve problems resulting from the lack of access to care. ${ }^{14-18}$ Clearly, an improvement in the accessibility of trained oral health professionals is warranted; however, because of the inequitable distribution of the dental workforce, it is unlikely that this shortage will be remedied by dentists alone. Despite this fact, attempts by others such as the dental therapists in Alaska or expanded-duty dental hygienists to augment the oral health team have not been generally well received by the dental profession. This lack of acceptance prevails despite the presence of clear and documented successes by allied dental health professionals like the long-standing dental therapists of New Zealand. While the incidence of decayed, missing, and filled teeth (DMFT) of children in New Zealand is roughly comparable to that of children in the United States, the existence of school-based dental clinics led by dental nurses has led to essentially decay-free mouths for school-aged children in New Zealand when epidemiological studies are done at the end of the school year. ${ }^{19}$ In the United States, alternate approaches to meeting oral health care needs have included expansion of the dental team through allied oral health care professionals such as the advanced dental hygiene practitioner(ADHP) introduced by the American Dental Hygienists' Association (ADHA) ${ }^{20}$ and the oral preventive assistant (OPA) ${ }^{21}$ Recently, the American Dental Association (ADA) introduced the concept of a community dental health coordinator (CDHC), a new team member who would be specifically trained to help organize community programs and function in remote locations and other underserved areas. ${ }^{21}$

Expanding the roles and decreasing the limitations placed on the scope of practice of non-dentist members of the oral health care team would likely be an effective strategy, particularly in rural areas or locations where there is a shortage of dentists. While a more empowered oral health team would be beneficial, we contend that the introduction of physicians or other strategic members of current general health care teams is just as important to meeting the overall health care needs of the public. A two-way stream of collaboration between dental and medical teams, fostered by educational staging (IPE in all units of the health sciences) as well as the redesign of physical premises departing from the trend of separate dental and medical offices and clinics, must ultimately lead to more effortless exchange of information between medical and dental health care settings. Such collaboration might include referrals, labs, treatment requests, and precautions; more comprehensive practice of dentistry and medicine; and earlier detection of both oral and systemic diseases - all leading to decreased national health care costs.

This emphasis on IPE needs to occur while the dental student is being educated. Providing a classroom and clinical environment where collaborative behaviors can be modeled and practiced by students would offer a means to help reinforce concepts and model appropriate patient care and interprofessional collaboration. Utilizing community sites that serve at-risk populations would also help to address the disparities in health care highlighted by the surgeon general's report ${ }^{2}$ and the National Call to Action to Promote Oral Health issued by the National Institutes of Health. ${ }^{22}$ A series of articles by Mouradian et al. and other authors called for dental-medical collaboration as a way to address these needs. ${ }^{23-29}$ A number of promising models are described; often missing, however, are the dental student and a strong leadership role from dental education to train our future professionals to work collaboratively as part of an interprofessional health care team.

Understandably, the shift toward IPE will require modification of some aspects of the dental education curriculum. In July 2007, the American Dental Education Association (ADEA) Commission on Change and Innovation in Dental Education 
(CCI), through an ADEA-Commission on Dental Accreditation (CODA) Task Force, distributed a document containing recommendations for changes to the predoctoral accreditation standards. Among them are additions under Standard 5, Patient Care Services. The recommended additions and their intent are as follows: ${ }^{30}$

- Students must be competent to collaborate with other health care providers in providing patient care. Intent: Oral health is fundamental to systemic health. Effective patient care requires collaboration and communication among health care providers. To the extent possible, students should have educational experiences, particularly clinical experiences, that involve working with other health professions students and practitioners.

- Dental education programs must make available sufficient opportunities and encourage students to engage in structured learning experiences that combine community service with preparation and reflection (service-learning). Intent: Students should learn professional responsibility to address the needs of the community, particularly those not served and underserved. To assist and encourage students to participate in service-learning, dental schools should seek partnerships in their communities with private practice dentists and other health care professionals to provide patient care through faculty and students.

These recommendations appear to be a good starting point or common denominator across dental education. Even so, we must ask if such standard changes would materially affect the culture of dental education. This idea of cultural change or evolution was discussed by Cohen when he postulated that, over time, dentistry will integrate completely with medicine based on convergent cultural evolutionary trends. ${ }^{31}$ Still, if this integration is inevitable, then dentistry must be at the forefront of any initiative leading to such change.

\section{Barriers to Implementation}

Educating students to interact as an interdisciplinary health care team is a major challenge for the health care professions. Historically, medical, dental, nursing, and allied health programs have provided very little direct, collaborative, interdisciplinary education for their students. Health professionals are trained in isolation, with long-standing interprofessional and intraprofessional rivalries. Most faculty teach in a cloistered environment and are not adequately prepared to teach skills needed to foster interdisciplinary collaboration and joint decision making. ${ }^{32,33}$ A lack of knowledge and skills of other disciplines fuels interdisciplinary rivalry. Fears that professional identity and power may be diluted through an interdisciplinary focus can manifest as a lack of cooperation, with disciplines defending their authority at the expense of the overall process. ${ }^{34}$ Furthermore, a lack of financial incentives and limitations makes it difficult to obtain consistent funding streams to sustain core programs or model innovations in education and practice. ${ }^{35}$ Nonetheless, various attempts have been made to cross-train students from different health professions. Indeed, examples of programs within the domain of IPE in the United States have been described in the literature since at least the 1940s. ${ }^{36}$ The disciplines involved have varied by program, as have content and sites in which programs have been conducted. Much of the early literature on programs in both the United States and abroad is descriptive in nature and describes pilot programs only. Programs ended when funding stopped and/or they lacked outcome information.

With respect to dentistry's role as part of comprehensive health care teams, a review of the literature shows only limited inclusion of oral health care professionals as members of interdisciplinary teams. ${ }^{8,23,24,37-41}$ The fact that many dental professionals do not perceive urgency in the call for IPE should come as no surprise to those involved with dental education. Rather than integrating dentistry within a comprehensive interdisciplinary health care education system, most of academic dentistry has continued to opt for an isolated, insular approach to training future dentists. ${ }^{42}$ This silo approach to education, a distinct professional code of ethics, and the drawing of boundaries around professional knowledge all undermine respectful awareness of the knowledge and skills of other disciplines. ${ }^{43}$ Furthermore, with an already saturated curriculum, professional educators in dentistry object to further intrusions of a "new subject area" into their curricula. Although a growing push for dental education reform has resulted in some curricular changes ${ }^{43-47}$ nearly 90 percent of North American dental schools surveyed in 2002 operated a traditional discipline-based (silo) curriculum, and only a handful reported interdisciplinary curriculum organization. ${ }^{48}$ Reasons cited were that the process of curriculum modification is "slow and difficult," "departments remain territorial," and "change is a slow and humbling process." In the same survey, 
respondents were asked what curricular innovations they had planned for the next four years. Only 48 percent of the schools planned more curricular emphasis on medical problems, and only 52 percent planned to increase educational collaborations with other schools on campus. ${ }^{48}$

IPE is often viewed as a fad by educators and not perceived as a high priority. Admittedly, the lack of scientific evidence of the effectiveness of IPE and the absence of outcome studies showing that interdisciplinary teams result in better care ${ }^{9,10}$ make it hard to justify the time and effort needed to widely implement IPE. ${ }^{46}$ Despite these barriers, if we, as dental educators, do not place sufficient value on integrating oral health within the context of primary health, ${ }^{8}$ we cannot expect our graduates to do so in their practices. If we do not provide, as an integral part of the dental curriculum, opportunities for our students to collaborate with other health professionals, we should not expect them to value collaboration after graduation.

\section{Changing the Culture of Dental Education}

If we accept the need to incorporate IPE within the dental education curriculum as a means to help address the nation's oral health crisis, the inevitable question is how this can be accomplished given the wide array of barriers and new paradigms to adopt. It is our firm belief that in order to implement IPE in the dental curriculum the following strategies must occur:

- Faculty Development: First and foremost, the importance and value of IPE must be conveyed to the academic community of dental educators. It is unrealistic to expect that all faculty members will eagerly engage in this process unless faculty development programs designed to educate and enlighten are initiated at each academic institution. The proposed recommendations of the ADEACODA Task Force working in conjunction with the ADEA CCI place considerably more emphasis on professional development of the faculty as a core responsibility of the dental school and describe the critical role of faculty to the cultivation of an academic environment that supports and sustains innovation. For example, the proposed changes to the predoctoral standards under Standard 5, Patient Care Services emphasized the need for dental students to be competent to collaborate with other health care providers. ${ }^{30}$ Faculty development, initiated and required by academic institutions, is necessary to cultivate the necessary skills and experiences for faculty members, so they can then teach and model these behaviors and skills with their students.

- IPE Initiatives: Many institutions have existing interprofessional initiatives that involve multiple colleges and disciplines. Dental school leaders need to ensure complete and proactive participation in these activities. Universities and health science centers that do not have such programs should create the opportunity for dental schools to take the lead and develop campus-wide interprofessional teams and activities. Those schools not affiliated with academic health centers can partner with community centers to identify sites and methods for students and faculty to work with multiple professions in providing care to underserved populations.

- Curricular Changes: The biggest challenge-incorporating IPE into the dental curriculum - would necessitate recommendations for both didactic and clinical changes and would further require collaboration with multiple professions. Ideally, course material on IPE would begin as early as the first year and continue throughout the curriculum to include appropriate content and competencies. Content for the curriculum should acknowledge the historical role dentistry has played in important preventive measures such as fluoridation, sealants, and oral hygiene. Topics integral to dentistry that cross interprofessional lines (for example, the aging population, special needs, craniofacial defects, pediatrics, medical/dental therapeutics, and identification of risk factors for oral and systemic disease) would highlight the connections between oral health and general health. Students must be able to develop and present models of interprofessional practice that emphasize the benefits of a multidisciplinary approach and address these complex health issues. The values promoted in formal courses must also be reflected in clinical practice settings. ${ }^{9}$ The access to care problem and health care crisis that drive the move toward IPE provide a logical starting point to identify community centers attempting to address the needs of the underserved. Existing facilities, frequently staffed (or understaffed) by medical and nursing personnel, offer a venue for dental students and faculty to teach, learn, and serve collaboratively. Rotations 
in hospitals, head and neck cancer clinics, and nursing homes provide additional opportunities for interprofessional learning.

Any cultural change will require support from the university administration, health care units within the parent institution, and existing public health initiatives. As indicated in the surgeon general's report, reformation of the dental curriculum will mandate input from all stakeholders including collaborations among individuals, health care providers, communities, and policymakers at all levels of society in order to help share and shape common goals for IPE. ${ }^{2}$ It is encouraging that both universities and state health departments have called for better integration of dental schools with other units on campus and the development of partnerships with public health centers, respectively. ${ }^{49}$

\section{Conclusion}

If IPE is to occur, dentistry must take the lead and look outside of traditional educational and practice paradigms. To make this happen, dental education has to be reformed to include curricular content and clinical experiences with other members of the health care team including physicians, nurses, and other care providers. Every dental school must address this issue if the profession is to continue to be the primary provider of oral care to the public. This effort needs the support of the administrators, stakeholders, legislators, faculty, students, and alumni. In this age of curriculum reform, will dental education take a bold move toward IPE, or will it be business as usual?

\section{Acknowledgments}

The authors would like to thank Dr. Brad Potter for his guidance throughout the ADEA Leadership Institute. We also acknowledge Dr. John N. Williams, Dr. Cecile Feldman, and Dr. Karl Haden for their valuable contributions.

\section{REFERENCES}

1. Mertz E, O'Neil E. The growing challenge for providing oral health care services to all Americans. Health Aff (Millwood) 2002;21(5):65-77.

2. Oral health in America: a report of the surgeon general. Rockville, MD: U.S. Department of Health and Human Services, National Institute of Dental and Craniofacial Research, National Institutes of Health, 2000:308.

3. American Dental Education Association. Statement on health care programs. In: Position papers, as approved by the 2003 House of Delegates. J Dent Educ 2007; 71(7):939.

4. Institute of Medicine. Health professions education: a bridge to quality. Washington, DC: National Academies Press, 2003.

5. Rafter ME, Pesun IJ, Herren M, Linfante JC, Mina M, Wu $\mathrm{CD}$, Casada JP. A preliminary survey of interprofessional education. J Dent Educ 2006;70(4):417-27.

6. Pyle M, Andrieu SC, Chadwick DG, Chmar JE, Cole JR, George $\mathrm{MC}$, et al. The case for change in dental education. J Dent Educ 2006;70(9):921-4.

7. DePaola DP. The revitalization of dental education. J Dent Educ 2008;72(2 Suppl):28-42.

8. Haden NK, Catalanotto FA, Alexander CJ, Bailit H, Battrell A, Broussard J Jr, et al. Improving the oral health status of all Americans: roles and responsibilities of academic dental institutions. The report of the ADEA president's commission. J Dent Educ 2003;67(5):563-83.

9. Zwarenstein M, Reeves S, Barr H, Hammick M, Koppel I, Atkins J. Interprofessional education: effects on professional practice and health care outcomes. Cochrane Database Syst Rev 2001;1:CD002213.

10. Reeves S, Zwarenstein M, Goldman J, Barr H, Freeth D, Hammick M, Koppel I. Interprofessional education: effects on professional practice and health care outcomes Cochrane Database Syst Rev 2008;1:CD002213.

11. Campbell JC, Coben JH, McLoughlin E, Dearwater S, Nah G, Glass N, et al. An evaluation of a system-change training model to improve emergency department response to battered women. Acad Emerg Med 2001;8(2):131-8.

12. Morey JC, Simon R, Jay GD, Wears RL, Salisbury M, Dukes KA, et al. Error reduction and performance improvement in the emergency department through formal teamwork training: evaluation results of the MedTeams project. Health Serv Res 2002;37(6):1553-81.

13. Berenson A. Boom time for dentists, but not for teeth. New York Times, October 11, 2007.

14. Skinner AC, Slifkin RT, Mayer ML. The effect of rural residence on dental unmet need for children with special health care needs. J Rural Health 2006;22(1):36-42.

15. The 2004 report to the secretary: rural health and human service issues. Washington, DC: National Advisory Committee on Rural Health and Human Services, April 2004.

16. Report to congressional requestors: oral health — dental disease is a chronic problem among low-income populations. Washington, DC: U.S. General Accounting Office, April 2000

17. Dental, Oral, and Craniofacial Data Resource Center, National Institute of Dental and Craniofacial Research, National Institutes of Health and Division of Oral Health, Centers for Disease Control and Prevention. Oral health U.S., 2002. At: http://drc.hhs.gov/report/pdfs/OralHealth figures.pdf. Accessed: February 2008.

18. Kinlaw DH. Access to dental care: a historical review of Medicaid eligibility growth and dental productivity decline. J Dent Educ 2001;65(9):849-60.

19. Nash DA, Nagel RJ. Confronting oral health disparities among American Indian/Alaska Native children: the pediatric oral health therapist. Am J Public Health 2005;95(8):1325-9. 
20. American Dental Hygienists' Association. Advanced dental hygiene practitioner fact sheet. At: www.adha. org/media/facts/adhp.htm. Accessed: March 2008.

21. McKinnon M, Luke G, Bresch J, Moss M, Valachovic RW. Emerging allied dental workforce models: considerations for academic dental institutions. J Dent Educ 2007;71(11):1476-91.

22. National call to action to promote oral health. NIH Publication No. 03-5303. Rockville, MD: U.S. Department of Health and Human Services, Public Health Service, National Institutes of Health, National Institute of Dental and Craniofacial Research, May 2003.

23. Mouradian WE, Berg JH, Somerman MJ. Addressing disparities through dental-medical collaborations, part I: the role of cultural competency in health disparities - training of primary care medical practitioners in children's oral health. J Dent Educ 2003;67(8):860-8.

24. Mouradian WE, Corbin SB. Addressing health disparities through dental-medical collaborations, part II: cross-cutting themes in the care of special populations. J Dent Educ 2003;67(8):1320-6.

25. Mouradian WE, Huebner C, DePaola D. Addressing health disparities through dental-medical collaborations, part III: leadership for the public good. J Dent Educ 2004;68(5):505-12.

26. Pyle MA, Stoller EP. Oral health disparities among the elderly: interdisciplinary challenges for the future. J Dent Educ 2003;67(12):1327-36.

27. Fenton SJ, Hood H, Holder M, May PB, Mouradian WE. The American Academy of Developmental Medicine and Dentistry: eliminating health disparities for individuals with mental retardation and other developmental disabilities. J Dent Educ 2003;67(12):1337-44.

28. Rozier RG, Sutton BK, Bawden JW, Haupt K, Slade GD, King RS. Prevention of early childhood caries in North Carolina medical practices: implications for research and practice. J Dent Educ 2003;67(8):876-85.

29. Mouradian WE, Schaad DC, Kim S, Leggott PJ, Domoto PS, Maier R, et al Addressing disparities in children's oral health: a dental-medical partnership to train family practice residents. J Dent Educ 2003;67(8):886-95.

30. Haden NK, ADEA Commission on Change and Innovation. Personal communication, December 2007.

31. Cohen MM Jr. Major long-term factors influencing dental education in the twenty-first century. J Dent Educ 2002;66(3):360-73.

32. Holmes DE. Catalysts in interdisciplinary education. Washington, DC: Association of Academic Health Centers, 1999.

33. Greiner A. Educating health professionals in teams: current reality, barriers, and related actions. Washington, DC: Institute of Medicine, 2002.
34. Whitehead C. The doctor dilemma in interprofessional education and care: how and why will physicians collaborate? Med Educ 2007;41(10):1010-16.

35. Lary MJ, Lavigne SE, Muma RD, Jones SE, Hoeft HJ Breaking down barriers: multidisciplinary education model. J Allied Health 1997;26(2):63-9.

36. Baldwin D. Some historical notes on interdisciplinary and interprofessional education and practice in health care in the U.S. J Interprof Care 1996;10:173-87.

37. Nowjack-Raymer RE. Teamwork in prevention: possibilities and barriers to integrating oral health into general health. Adv Dent Res 1995;9:100-5.

38. Johnston GM, Ryding HA, Campbell LM. Evolution of interprofessional learning: Dalhousie University's "From family violence to health" module. J Can Dent Assoc 2003;69(10):658.

39. Reeves S, Pryce A. Emerging themes: an exploratory research project of an interprofessional education module for medical, dental, and nursing students. Nurse Educ Today 1998;18:534-41.

40. Mouradian WE, Reeves A, Kim S, Evans R, Schaad D, Marshall SG, et al. An oral health curriculum for medical students at the University of Washington. Acad Med 2005;80(5):434-42.

41. Kalet AL, Juszczak L, Pastore D, Fierman AH, Soren K, Cohall A, et al. Medical training in school-based health centers: a collaboration among five medical schools. Acad Med 2007;82(5):458-64.

42. Nash DA. Oral physician redux: theses for a (major) reformation of dental education. Topic paper presented at the Santa Fe Group Planning Conference, August 29, 2004.

43. DePaola DP, Slavkin HC. Reforming dental health professions education: a white paper. J Dent Educ 2004;68(11):1139-50.

44. Field MJ, ed. Dental education at the crossroads: challenges and change. An Institute of Medicine report Washington, DC: National Academy Press, 1995.

45. Tedesco LA. Issues in dental curriculum development and change. J Dent Educ 1995;59(1):97-147.

46. Hendricson WD, Cohen PA. Oral health care in the twentyfirst century: implications of dental and medical education. Acad Med 2001;76(12):1183-5.

47. Donoff RB. It is time for a new Gies report. J Dent Educ 2006;70(8):809-19.

48. Kassebaum DK, Hendricson WD, Taft T, Haden NK. The dental curriculum at North American dental institutions in 2002-03: a survey of current structure, recent innovations, and planned changes. J Dent Educ 2004;68(9):914-31.

49. Davis EL, Stewart DCL, Guelmann M, Wee AG, Beach JL, Crews KM, Callan RS. Serving the public good: challenges of dental education in the twenty-first century. J Dent Educ 2007;71(8):1009-19. 